\section{Birth asphyxia}

Birth asphyxia is often blamed, sometimes wrongly, when a child is found to have a neurological handicap. Estimates of its incidence in Britain and the United States in the 1960 s and early. 1970 s have varied from $1.2 \%$ to $5 \%$ of births $^{1-3}$ (and of severe asphyxia $0.4 \%$ to $1.6 \%{ }^{14}{ }^{4}$ ), but the figures may have changed recently because of the widespread introduction of continuous intrapartum fetal monitoring. I shall attempt to answer, in the light of recently published information, five questions which are of great concern to paediatricians and all those concerned with the care of babies and children.

Firstly, what is the risk of death or of permanent severe handicap for the baby with severe birth asphyxia? Several publications have attempted to answer this question in relation to the baby "born dead" (Apgar score of 0 ). All have concluded that the prognosis for babies who survive is not as bad as had been thought and that prompt, skilled resuscitation gives these babies a good chance of normal development if they survive the newborn period. Scott reported on 15 such babies born at the Hammersmith Hospital between 1966 and 1971, of whom eight died-but six of the seven survivors were normal when examined three to seven years later. ${ }^{4}$ In Aberdeen between 1964 and 1968 four babies had a 1 minute Apgar score of 0 . Two died but the two survivors were normal at follow-up. ${ }^{5}$ In Newcastle between 1961 and 1970 there were six survivors of 14 babies born with no heart beat. ${ }^{6}$ Four were normal at follow-up and two were severely abnormal with spastic quadriparesis.

The Apgar scoring system ${ }^{7}$ is now used routinely in most maternity units and is the basis of many recent papers on the outcome of birth asphyxia. All the studies confirm that severe asphyxia is associated with a high neonatal mortality (about $50 \%$ ) but a good chance of normal development in survivors. In the Hammersmith Hospital series 33 babies had Apgar scores of 1 or 2 at 1 minute and did not breath spontaneously in the first 20 minutes. ${ }^{4}$ Sixteen of these 33 babies survived the first month and five had signs of cerebral palsy on follow-up, of whom two were very severely handicapped and the others were thought to have a good chance of leading reasonably full and independent lives. In Aberdeen 41 of 82 babies with 5 minute Apgar scores of less than four survived the neonatal period. ${ }^{5}$ Twenty-nine of the 41 were examined at between 5 and 10 years of age and 27 had no serious handicap. The other two were very severely handicapped with quadriplegia and very severe mental retardation. Of the 12 children not examined, three were lost to follow-up but there is evidence that the other nine were developing normally. In Birmingham, Alabama, 20 of 51 infants with 1 minute Apgar scores of less than four survived. ${ }^{8}$ Fifteen were examined at 22 to 40 months and three of these were severely handicapped. In Pittsburgh, Pennsylvania, $44 \%$ of babies who failed to breathe spontaneously in the first minute died and $18 \%$ of the survivors had serious sequelae, $8 \%$ having very severe mental retardation and cerebral palsy. ${ }^{2}$

A recent paper from the American National Collaborative Perinatal Project reported the Apgar scores and subsequent progress of about 49000 babies. ${ }^{1}$ The early mortality was $17 \%$ for 2764 babies with 1 minute scores of less than four and $44 \%$ for 780 babies whose 5 minute score was less than four. In 178 babies whose low score persisted for 20 minutes the mortality was $88 \%$. Low birth weight babies with a low Apgar score at 1 minute had a mortality of $48 \%(26 \%$ if the score had improved by 5 minutes) and at 20 minutes $96 \%$. Cerebral palsy causing substantial handicap occurred in $1.6 \%$ of the survivors of a low 1 minute score, $5 \%$ of those with a low 5 minute score, and $41 \%$ of those with a low 20 minute score. Cerebral palsy was less common in low birth weight babies with prolonged low scores than in babies of normal weight with similar scores, though the differences did not reach statistical significance. Almost all the children with cerebral palsy were severely mentally subnormal.

Secondly, what is the risk of minor handicap in the survivors of severe birth asphyxia? Most of the children who survive severe birth asphyxia without very severe handicap do well. Thompson and colleagues" concluded that asphyxia has an "all-or-none effect." In the Birmingham, Alabama, series the severely asphyxiated babies did not differ from controls as regards IQ or minor neurological abnormality once the severely handicapped survivors were excluded from the analysis. ${ }^{8}$ In the Collaborative Perinatal Project Study 87 children survived severe, prolonged asphyxia without disabling cerebral palsy. ${ }^{1}$ Six of these had speech defects and two were deaf. The incidences of visual defect, mental retardation, and hyperactivity did not differ from those found in the whole of the Collaborative Project population. D'Souza and his colleagues in Manchester recently reported on the hearing, speech, and language of 26 children who survived 1 minute Apgar scores of 0 or 1 between 1973 and $1976 .{ }^{9}$ One child had sensorineural deafness. Of 23 children tested, five had delayed language development and three had speech defects.

Thirdly, for how long should we persist in attempting to resuscitate a baby who does not breathe at birth ? Steiner and Neligan found that in babies who suffered cardiac arrest those who breathed spontaneously within 30 minutes of the return of the heart beat did well, but all four who survived more than 30 minutes of respiratory arrest after the return of the heart beat had quadriplegia and severe mental subnormality. ${ }^{6}$ In the Collaborative Perinatal Project ${ }^{1}$ a very low Apgar score persisting to 20 minutes was associated with $88 \%$ mortality and $41 \%$ of survivors had cerebral palsy. In term babies the incidence of severe cerebral palsy rose abruptly from $9 \%$ with asphyxia persisting for 15 minutes to $57 \%$ when asphyxia persisted for 20 minutes. In Manchester, however, none of seven babies whose failure to breath spontaneously lasted for more than 30 minutes was seriously damaged at follow-up. ${ }^{9}$ One important point is that the babies in the Collaborative Perinatal Project were born between 15 and 22 years ago and the figures may well be unduly pessimistic for the present day.

Before resuscitation is abandoned the doctor should be satisfied that drugs given to the mother are not the cause of the failure to breath, and treatable conditions such as pneumothorax or diaphragmatic hernia should be excluded. In a child who is hypotonic and unresponding continuing resuscitation beyond 30 minutes seems unlikely to result in a favourable outcome, but in a baby who is developing normal muscle tone, is pink, and is beginning to respond to stimulation more prolonged attempts to resuscitate may be justified.

Fourthly, how do antenatal factors affect prognosis for the asphyxiated baby? Asphyxia of acute onset may be less likely to produce long-term effects than prolonged intrauterine hypoxia. In an earlier Collaborative Project Study the survivors of placenta praevia, abruptio placentae, and prolapsed cord had no greater liability to neurological impairment than controls. ${ }^{10}$ In the Hammersmith Hospital study factors indicating prolonged intrauterine stress were present in four of six survivors with cerebral palsy and two of 17 normal 
survivors. ${ }^{4}$ Recent larger studies in Edmonton ${ }^{11}$ and Pittsburgh, ${ }^{2}$ however, have failed to show any correlation between antenatal adverse factors and the outcome in survivors of asphyxia. In studies in monkeys total asphyxia mostly damaged the brain stem whereas long-term partial intrauterine asphyxia damaged mainly the cerebral hemispheres, cerebellum, and basal ganglia. ${ }^{12}$ The latter pattern most closely resembles the pattern of human brain damage.

Finally, can neonatal examination predict long-term outcome? Most asphyxiated babies who are neurologically abnormal soon after birth recover completely. ${ }^{31314}$ In Manchester 55 babies were thought to show severe neurological abnormality in the first few days of life. ${ }^{13}$ Two died within the first two days, but of the 53 survivors only four had a definite neurological disorder on follow-up, and in only one was the disorder severe. The babies were divided into four categories on the basis of activity and tone: hyperexcitable; apathetic; apathetic early but hyperexcitable after two or three days; and normal tone with other neurological abnormality. Three of the four babies who had definite neurological abnormality at follow-up came from the group of seven who were initially apathetic and hypotonic but after two or three days became hyperexcitable and showed extensor hypertonia. An earlier Edinburgh series ${ }^{3}$ also found that this group of babies was at highest risk of later handicap. In that series certain clinical features were found to be predictive in combination: feeding difficulties, apnoeic spells, apathy, convulsions, hypothermia, cerebral cry, and persistent vomiting. Babies with five or more of these had a $90 \%$ risk of death or serious handicap. With only one symptom no baby died or had serious handicap.

Convulsions after birth asphyxia are of serious significance, especially when they are multiple and recur over a prolonged period. In the Collaborative Project Study $30 \%$ of babies with convulsions died and $18 \%$ of the survivors had severe handicap, ${ }^{14}$ but in a more recent study in Manchester only one of 22 babies who had convulsions had a severe neurological abnormality at follow-up. ${ }^{13}$

What, then, does all this mean in practice? Firstly, severe birth asphyxia does not have a universally gloomy prognosis, and skilled resuscitation should be available for all babies. The prognosis with prolonged asphyxia may be less favourable, but a decision to stop resuscitation should be made only after considering possible treatable causes. Failure to show any response after 30 minutes, however, is probably associated with a bad prognosis. Most survivors of birth asphyxia are normal, but a few are very severely handicapped. Lesser degrees of behavioural or educational abnormality in survivors have not been convincingly shown, though some of them have speech and language problems and may need special education. In the newborn baby convulsions after birth asphyxia are of serious import, especially if they are multiple and persistent, and the combination of early apathy followed after two or three days by hyperexcitability seems to carry a particularly poor prognosis.

D P ADDY

Consultant paediatrician,

Dudley Road Hospital,

Birmingham B18 7QH

1 Nelson KB, Ellenberg JH. Apgar scores as predictors of chronic neurologic disability. Pediatrics $1981 ; 68: 36-44$.

${ }^{2}$ Mulligan JC, Painter MJ, O'Donoghue PA, MacDonald HM, Allen AC, Taylor PM. Neonatal asphyxia. II. Neonatal mortality and long-term sequelae. F Pediat 1980;96:903-7.

${ }^{3}$ Brown JK, Purvis RJ, Forfar JO, Cockburn F. Neurological aspects of perinatal asphyxia. Dev Med Child Neurol 1974;16:567-80.

${ }^{4}$ Scott H. Outcome of very severe birth asphyxia. Arch Dis Child 1976;51: 712-6.
5 Thomson AJ, Searle M, Russell G. Quality of survival after severe birth asphyxia. Arch Dis Child 1977;52:620-6.

6 Steiner H, Neligan G. Perinatal cardiac arrest: quality of the survivors. Arch Dis Child 1975;50:696-702.

2 Apgar V. A proposal for a new method of evaluation of the newborn infant. Current Researches in Anaesthesia and Analgesia 1953;32:260-7.

${ }^{8}$ Dweck HS, Huggins W, Dorman LP, Saxon SA, Benton JW, Cassady G. Developmental sequelae in infants having suffered severe perinatal asphyxia. Am 7 Obstet Gynecol 1974;119:811-5.

${ }^{9}$ D'Souza SW, McCartney E, Nolan M, Taylor IG. Hearing, speech, and language in survivors of severe perinatal asphyxia. Arch Dis Child $1981 ; \mathbf{5 6}: 245-52$

10 Niswander KR, Friedman EA, Berendes H. Do placenta previa, abruptio placentae and prolapsed cord cause neurologic damage to the infant who survives? In: MacKeith $\mathrm{R}$, Bax, M, eds. Studies in infancy. London: Heinemann Medical, 1968:78-83. (Clinics in Developmental Medicine No 27.)

11 Finer NN, Robertson CM, Richards .RT, Pinnell LE, Peters KL. Hypoxic-ischaemic encephalopathy in term neonates: perinatal factors and outcome. $\mathcal{F}$ Pediatr 1981;98:112-7.

12 Adamsons K, Myers RE. Perinatal asphyxia. Causes, detection and neurologic sequelae. Pediatr Clin North $A m$ 1973;20:465-80.

${ }^{13}$ De Souza SW, Richards B. Neurological sequelae in newborn babies after perinatal asphyxia. Arch Dis Child 1978;53:564-9.

${ }^{14}$ Nelson KB, Ellenberg JH. Neonatal signs as predictors of cerebral palsy. Pediatrics $1979 ; 64: 225-32$.

\section{Information overload: solution by quality?}

Are there too many journals for even the most enthusiastic reader? Are important discoveries being missed because vital papers are buried in a mass of inferior ones ? Could and should limits be set on the numbers of articles or journals published? Though we may suspect that the answer to all these questions is yes, an opposite and optimistic conclusion emerges from an important new book: all these problems can be overcome by ignoring quantity and concentrating on quality. In this way, Coping with the Biomedical Literature concludes, the individual can still keep up to date by scanning relatively few journals, supplementing his efforts with specific searches in review articles, citation lists, and computer printouts as well as conversation in the "invisible college" of colleagues and fellow researchers. ${ }^{1}$

On the face of it the problems are daunting: for biomedicine there are now over 20000 journals, almost all of them received at the National Library of Medicine, in Bethesda, USA; 3200 of these are included in its Medical Literature and Retrieval System (Medlars) and 1000 in the Science Citation Index. The number of journals increases by $6-7 \%$ a year, doubles every 10-15 years, and increases tenfold every $35-50$ years. At the opening of this century there were roughly 1000 biomedical journals; 30 years ago there were 4000 and 10 years ago $14000 .^{2}$ True, some journals cease publication, but at a rate insufficient to affect this exponential growth.

There has been no lack of suggestions for dramatic action to restrict this growth, both Bernal ${ }^{3}$ and Fox $^{4}$ arguing for a division of journals into recorder or archival publications and newspaper or current awareness journals. Indeed, as long ago as 1939 Bernal suggested that the traditional scientific journal could be replaced by a system of distributing abstracts of articles sent to a central source, with interested readers obtaining copies of the full papers on request. Fox repeated Bernal's suggestions in his Heath-Clark lectures in 1964, ${ }^{4}$ going on to say that, as with the overgrowth of other populations, the preferable remedy was prevention-some form of contraception. Yet, though this concept was echoed as recently as 1979 by Durack (who proposed that each individual could 